\title{
Implementation of Product Design Tools for the Development of an Automated Vegetable Chopper
}

\author{
Subrata Talapatra, Md. Shakil, Pritom Kumar Mondal, Md. Saiful Islam \\ Department of Industrial Engineering \& Management (IEM), \\ Khulna University of Engineering \& Technology (KUET), Khulna, Bangladesh \\ Email: sub_ksy@yahoo.com, shakil.anowar@yahoo.com,pritom.ipe08@gmail.com, saifuliem@gmail.com
}

Received October 26, 2013; revised November 26, 2013; accepted December 3, 2013

Copyright (C) 2014 Subrata Talapatra et al. This is an open access article distributed under the Creative Commons Attribution License, which permits unrestricted use, distribution, and reproduction in any medium, provided the original work is properly cited. In accordance of the Creative Commons Attribution License all Copyrights @ 2014 are reserved for SCIRP and the owner of the intellectual property Subrata Talapatra et al. All Copyright (C) 2014 are guarded by law and by SCIRP as a guardian.

\begin{abstract}
In the era of industrialization, automatic machines become an integral part of human life. These machines help to reduce the time needed to do a specific task. Nowadays, human life becomes more competitive and faster than the previous. Automation brought about by technology has saved human effort and time to a large extent. Slicing vegetables are a risky and time-consuming task in our busy life. This project is aimed at solving above stated problems by introducing a special product named Automatic Vegetable Chopper. This chopper is mainly designed to reduce human effort and make the job of chopping vegetables much easier and faster. Its main features are fully automated, easily portable, less power consumption and changeable stainless, sharp blade, etc. This product is designed and established by following a structured product design process and with the help of a board of design engineers. Product planning, customer needs identifying, product specification, concept screening, concept scoring and bill of materials are tools that mainly used to accomplish this task. Finally, this paper also suggests various techniques and opportunities of product planning in manufacturing industries as future recommendations.
\end{abstract}

\section{KEYWORDS}

Automatic Machine; Chopper; Product Planning; Bill of Materials

\section{Introduction}

Product design is considered to be the most difficult, sensitive and critical in creating products [1]. It greatly influences the cost, robustness, manufacturability and development time of the final products [2]. As a rule of thumb, the cost of engineering changes increases by ten times when changes are made in a later stage. Product planning, customer needs identifying, product specification, concept screening, concept scoring and bill of materials are the basic tools for the development and design of a product. Designers use these concepts for the development of a product. This stage also includes comparing the relative strengths and weaknesses of the product, and determining concepts for further investigation, testing or development.

These phases significantly affect whether the final design will be exemplary, resulting in higher profits, or will have fundamental flaws that often require costly recalls. Many designers are challenged during this process by having to make many decisions with limited information. Many design methods have been developed to assist designers in making the correct decisions during the concept selection phase [3], including Pugh's concept scoring [4], analytic hierarchy process (AHP), fuzzy set [5], fuzzy AHP method [6], flexible design concept selection [7], hypothetical equivalents and in-equivalents method [8], and quality function deployment (QFD) [9]. Among these methods, the product planning, customer needs identifying, product specification, concept screening, concept scoring and bill of materials steps are most commonly used in industry [10]. In essence, concept scoring and the AHP method have fundamentally the same methodologies [11]. The concept scoring method is a numerically weighted Pugh method, while AHP is a more mathematic 
version of concept scoring that minimizes personal bias during the weighting and scoring. According to Yeo et al., concept scoring and AHP have been found to provide similar results, as long as the differentiation between the alternatives is sufficiently large. Furthermore, the simplest and most commonly used form of concept selection methods has also been found to be most applicable to support the fuzzy nature of concept selection [12]. However, limitations, such as uncertainty and inability to provide the information on the compatibility between design concepts, remain as challenges for the concept selection method [13]. According to Hu and Pieprzak, the fundamental set of principles that define good axiomatic design practice can help to facilitate the generation of good design [13].

This paper illustrates the design and development of an Automatic Vegetable Chopper. The product is designed and developed with the help of various product design tools like product planning, customer needs identifying, product specification, concept screening, concept scoring and bill of materials, etc. After carefully implementation of those tools, final product is designed and developed which is cheaper than the available in market.

\section{Available Features}

Automatic Vegetable Chopper is technically advanced, use in cutting different kinds of vegetables, fruits, and other food items. This chopper has the facility of automatic feeding and discharge which in turn saves time. These machines have tubular feed-throat that is use to cut different long shaped vegetables. Before this work automatic chopper or slicer available on the market was little bit larger and noisy. In that case this product will add a new perspective in household chores like chopping vegetables as well as it carries a sign of modern lifestyle and smartness. Following features are available in this product:

1) Changeable stainless, sharp blade.

2) Bakelite plastic body to resist fire caused by shortcircuits.

3) Conveyer belt made from food grade rubber.

4) Fully automated.

5) Easily portable.

6) Less power consumption.

7) Rechargeable battery.

\section{Components for the Development}

Automatic Vegetable Chopper is technically advanced and it consists of shafts, discs, blades and bushings are making using stainless steel that is easy to clean and hence hygienic. Commercial this vegetable cuter is made from aluminum body. Stainless steel slicing, grating, di- cing, cubing, striping, figure chips making blades fitted on aluminum disc. Stainless steel shaft is drive with help of $\mathrm{v}$ belt and suitable four pole totally enclosed fan cooled single or three phase squirrel cage electric motor. Basic components are:

1) Body (Bakelite Plastic)

2) Cutter Blade (Stainless Steel)

3) Pulley

4) Crankshaft Mechanism

5) D.C. Motor

6) Conveyor Belt

These components are designed in AutoCAD 2007; Designed components are represented in the following Figure 1.

Standard accessories of Automatic vegetable chopper machine:

1) Suitable four pole totally enclosed fan cooled single or three phase squirrel cage electric motor is supplied with vegetable cutter.

2) Five blades (3 different size e disc for slicing, $1 \mathrm{z}$ discs for grating, $1 \mathrm{~d}$ discs for cubes).

3) One number aluminum discharge plate, one auto feeder and one manual tubular feed-throat.

\section{Product Planning}

Product planning is a process of discussing and defining features of a product before its development. There are a number of phases to product planning, including gathering input, refining ideas, approving and designating projects and tasks, refining market requirements and beginning product development. Product planning is important for a number of reasons. One of the earliest stages of product planning is gathering input about a new product idea. All perspectives are important, but pay close attention to customer feedback. A survey to ask existing customers about features they want and price would pay, as well as any other details specific of product.

The mission of Automatic vegetable chopper devel-

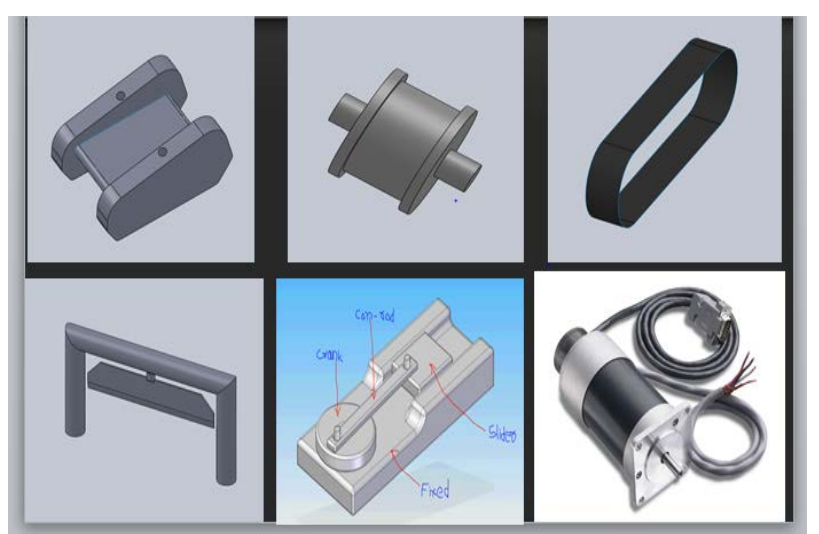

Figure 1. Designed components for the automatic vegetable chopper in AutoCAD 2007. 
opment is to be the leader in the Kitchen accessories market, providing easy chopping solutions that accelerate cooking activity. A key element of Automatic vegetable chopper's competitive strategy is to exploit technological innovation in a rapidly changing market. Product plan identifies the portfolio of products to be developed by the organization and the timing of their introduction to the market. The planning process considered product development opportunities identified by many sources, including suggestions from marketing, research, customers, current product development teams, and benchmarking of competitors. The product plan is regularly updated to reflect changes in the competitive environment, changes in the technology and the information of the success to existing product.

There are four types of product development process:

1) New product platforms

2) Derivatives of existing product platforms

3) Incremental improvements to existing products

4) Fundamentally new products

Automatic vegetable chopper is under the third category that is incremental improvements to existing products. While developing Automatic vegetable chopper these points are focused: low cost, ease of dis-assemble and re-assemble, safety issues, efficiency, available machineries, ease of maintenance and carrying. For the development of a product plan and project mission statements, there are four possible steps which Automatic vegetable chopper development team follows:

\subsection{Identify Opportunities}

For the design and development of the product, ideas have been gathered from the sources: Sales personnel from house-hold utensils stores of various markets (New market, Railway market, Jolil-tower), Technology development organizations (IEEE-KUET, HACKS-KUET), Product development team, Current customers (housewives, bachelors, hostel-girls) [Here some places and organization mentioned that is from Bangladesh].

\subsection{Evaluate and Prioritize Projects}

There are several stages are followed for the design and development of the “Automatic vegetable chopper”. These stages are classed as Competitive strategy and Market segmentation.

Competitive strategy:

1) Technology leadership: To implement this strategy “Automatic vegetable chopper" here emphasized on some advanced technology featured equipment e.g. specially designed conveyor belt, stainless cutting blade, speed controller and self-switching.

2) Customer focus: Automatic vegetable chopper development is focused on customers changing needs and preferences. The features of customer interest are implemented in this product (rapid and easy cutting, greater safety)

3) Imitative: A Japanese company named "YOUKU" has made great improvement to vegetable chopper. Automatic vegetable chopper development has nearly followed their technology.

Market segmentation: Automatic vegetable chopper development team has segmented the market into the following two categories.

1) Large: It is for restaurants and hotels;

2) Small: it is for house-hold usages.

S-Curve Framework for market segmentation:

Usually the S-curve is represented in Figure 2 as the variation of performance in function of the time/effort. Probably that is the most used metric because it is also the easiest to collect data for. This fact does not imply, however, that performance is more accurate than the other possible metrics, for instance the number of inventions, the level of the overall research, or the profitability associated with the innovation. In the innovation management field the S-Curve illustrates the introduction, growth and maturation of innovations as well as the technological cycles that most industries experience. In the early stages large amounts of money, effort and other resources are expended on the new technology but small performance improvements are observed. Then, as the knowledge about the technology accumulates, progress becomes more rapid. As soon as major technical obstacles are overcome and the innovation reaches a certain adoption level an exponential growth will take place.

\subsection{Allocating Resources and Plan timing}

Automatic vegetable chopper development team has invested its maximum resources in efficient blade design, long lasting motors, non-corrosive materials for its body.

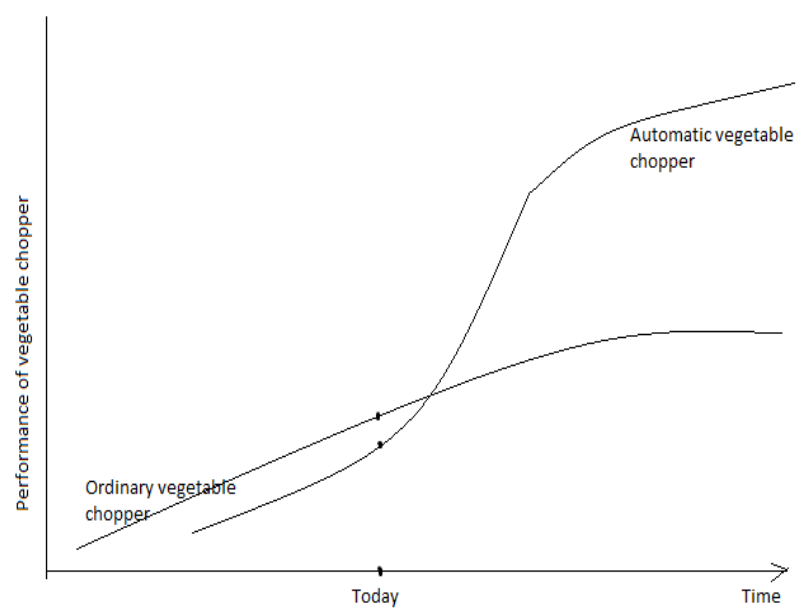

Figure 2. Technology S-curve for automatic vegetable chopper. 
This team projected the timing of the product on the basis of technology readiness, market readiness and competition.

\subsection{Complete Pre-Project Planning}

Product Vision Statement: Develop a fastest, safe, automatic vegetable chopper for chopping.

Mission Statements showing in Table 1.

\section{Identifying Customer Needs}

The philosophy behind the method of identifying customer needs is to create a high quality information channel that runs directly between customers in the target market and the developers of the product. This philosophy is built on the premise that those who directly control the details of the including engineers and industrial designers must interact with customers and experience the using environment of the product. Without this direct experience technical trade-offs are not likely to be made correctly, innovative solutions to customer needs may never be discovered and the development may never develop a commitment to meet customer needs.

Steps used for identifying customer needs are discussed as follows.

\subsection{Gather Raw Data from Customers}

1) Interview: The product development team interviewed several persons about the product. Some of them are satisfied what they are using but most of them have expressed their problem and discussed what features should be added for the ease of the use.

2) Focused Groups: The main group upon which the product development team is focused is women than the bachelor men because women do the kitchen course most of the time whereas the bachelor men have to do it for themselves since they have no female to do this.

3) Observing the Product in Use: Watching customers' use an existing product was intended can reveal important details about customer needs while using the present product that means various kinds of vegetable chopper the users often face a common problem which was cutting finger issues. It is also tiring and time consuming too.

\subsection{Interpret Raw Data in Terms of Customer Needs}

Customer needs are expressed as written statement and the results of interpreting the need underlying the raw data gathered from the customers. When the product development team surveyed they got the customer statement which they had turned into needs statements are given in Table 2.

\subsection{Organize the Needs into a Hierarchy}

The goal of this step is to organize the needs into a hierarchy list. The needs product development is found can be classified into three categories:

1) Primary (Implementing automation, safety issues, re-assemble the knives etc.)

2) Secondary (Easy to maintain, compactness etc.)

3) Tertiary (The light source)

Table 1. Product mission statement.

\begin{tabular}{|c|c|}
\hline Mission statement & Automatic Vegetable Chopper \\
\hline Product description & A hand-held, power assisted chopper for chopping vegetable of desired shape and size \\
\hline Benefit proposition & It can be operated swiftly, Easily with less effort, Can be operated with safety \\
\hline Primary market & Capture $80 \%$ of product sales in primary market. House-hold uses. \\
\hline Secondary market & Hotel, hostel uses. \\
\hline Assumptions and constraints & $\begin{array}{l}\text { Incremental improvements to existing products. Hand-held Power assisted Recharge-able battery technology. } \\
\text { Cutting blade manufactured in Germany. }\end{array}$ \\
\hline Stakeholder & Consumer, Retailer, Manufacturer, Distributor \\
\hline
\end{tabular}

Table 2. Raw data of customer needs.

\begin{tabular}{cc}
\hline Customer Statements & Needs statements \\
\hline I like lighter far more than match sticks & Implement automation \\
Most of the times I cut my fingers & Safety issues should be taken in sight \\
Can I use it while performing another work? & Easy to operate \\
I prefer smaller product & Product should be compacted and easy to maintain \\
I can't work in dark & A source of light is needed \\
I need to cut in various sizes & Able to re-assemble the knives \\
Rust irritates me most & Stainless steel for knives
\end{tabular}




\subsection{Establish the Relative Importance of the Needs}

The outcome of this step is a numerical importance waiting for a subset of the needs. There are two basic approaches to the task:

1) Relying on the consensus of development team's experience with customers.

2) Basing the importance assessment on further customer surveys.

\section{Concept Selection}

A matrix used to display how well different alternatives meet the list of product or process specifications or requirements. A concept selection matrix is organized by the requirements, and includes numerical values for target specifications as well as observed specifications for a list of potential solutions. For the development of this product follows two-step method for concept selection. These two methods are: Concept screening \& Concept scoring.

\subsection{Concept Screening}

The purpose of Concept Screening is to narrow the number of concepts quickly and improve the concepts. The concept screening includes the following six steps that is:

1) Preparing the selection matrix

2) Rating the concepts

3) Ranking the concepts

4) Combining and improve the concepts

5) Selecting one or more concepts

6) Reflect on the result and the process

These five steps are maintained for development of Automatic Vegetable Chopper in the following way:

Step 1: For preparing the selection matrix Automatic Vegetable Chopper development team entered the concepts along the top of the matrix and the selection criteria is entered along the left hand side of the selection matrix. While choosing criteria Automatic Vegetable Chopper development team tried to give equal weight of various criteria and the unimportant criteria are neglected.

Step 2: For rating the concepts Automatic Vegetable Chopper development team has used a relative score of "better than" (+), "same as" (0), and "worse than" $(-)$ in each cell of matrix.

Step 3: Here Automatic Vegetable Chopper development team has made the summation of all "better than", "same as", and "worse than" scores and entered the sum for each category in the lower rows of the matrix. After summation we rank orders the concepts and the concepts containing more pluses and fewer minuses ranked higher.

Step 4: After rating and ranking the concepts Automatic Vegetable Chopper development team combined and improved some concepts. The combined and improved concepts are added in the matrix.

Step 5: After completing all of the above activities Automatic Vegetable Chopper development team selected three concepts and concept scoring stage with its weighted selection criteria and more detailed rating used.

\subsection{Concept Scoring}

Concept scoring used for differentiate better resolution among competing concepts. Here "Automatic Vegetable Chopper" development team weights the relative importance of the selection criteria and tried to focus on more refined comparisons with respect to each criterion. The concept screening includes the following five steps.

1) Preparing the selection matrix

2) Rating the concepts

3) Ranking the concepts

4) Combining and improve the concepts

5) Selecting one or more concept

Step 1: In this step Automatic Vegetable Chopper development team prepared a matrix in a similar way and identified a reference point. Here added importance weights to the matrix for all criteria and these weights are determined subjectively by all Automatic Vegetable Chopper development team members.

Step 2: Here Automatic Vegetable Chopper development team rated all the concepts with respect to one reference criteria a fine scale of 1 to 5 is used for their rating.

Step 3: After entering all the concepts after calculated the weighted scores by multiplying the raw scores by the criteria weights. The total score for each concept is the sum of the weighted scores. Automatic Vegetable Chopper development team had tried to give each concept a rank corresponding to its total score.

Step 4: After completing all the above steps the Automatic Vegetable Chopper development team takes the decision of combining some concepts and making some improvements.

Step 5: After completing all of the above activities the Automatic Vegetable Chopper development team selected two concepts. The Automatic Vegetable Chopper development team selected the concepts by varying some weights and ratings.

\section{Bill of Material}

Table 3 shows the bill of material of automated vegetable chopper.

\section{Break Even Point}

Break-even point (BEP) is the point at which cost or expenses and revenue are equal: there is no net loss or gain, 
and one has "broken even." A profit or a loss has not been made, although opportunity costs have been "paid," and capital has received the risk-adjusted, expected return. It is shown graphically as the point where the total revenue and total cost curves meet. In the linear case the break-even point is equal to the fixed costs divided by the contribution margin per unit, showing in Figure 3.

So the cost of producing one unit of product will be 1165 TK (BDT) and the break-even point is originated in 511 units.

\section{Results and Discussion}

Concept screening: The concept screening of Automatic Vegetable Chopper is set below showing in Table 4, performance rating in Table 5 and concept scoring in
Table 6.

\section{Conclusion}

Product is the life of a company. It can determine the success and failure of companies. A good product can make a company live in a long-term success based on a good design. Product design reflects the economy, technology and culture of a company. The importance of product design is to be realized by managers. That is why more and more new-tech products appear in our life. The design and development of an automatic vegetable chopper gets perspectives on product design tools. This paper also shows the implementation of product planning, customer needs identifying, product specification, concept screening, concept scoring and bill of materials for the

Table 3. Bill of Material (BOM).

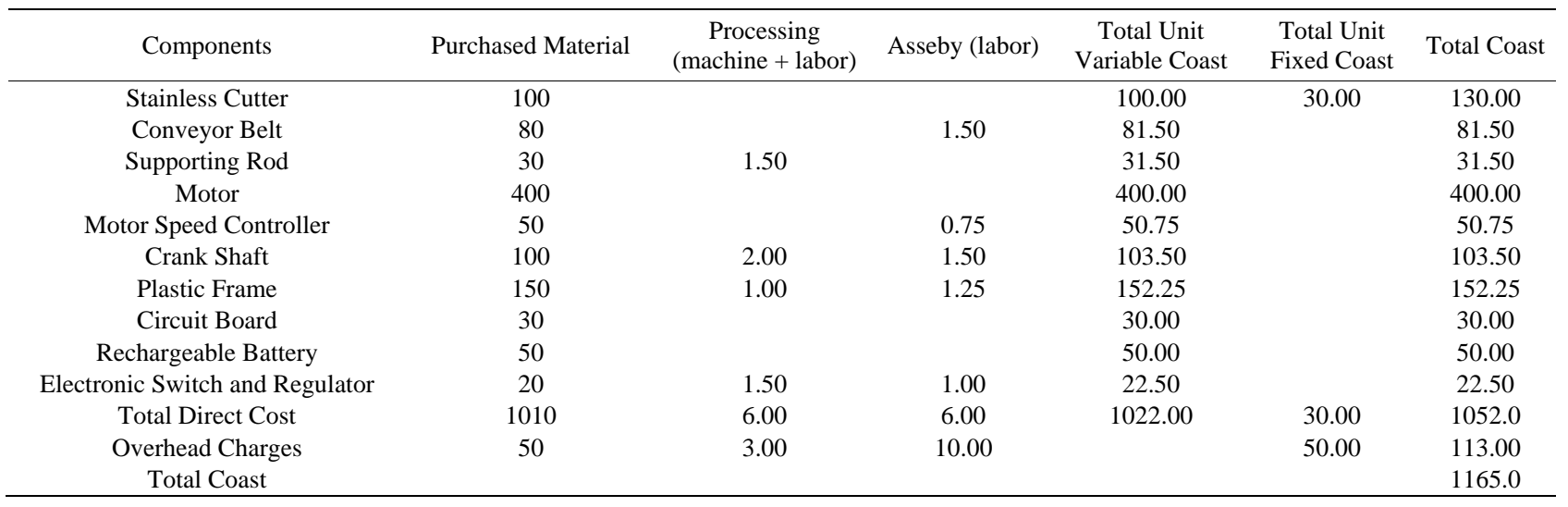

Table 4. Raw data of customer needs.

\begin{tabular}{|c|c|c|c|c|c|}
\hline Selection Criteria & A Conveyer belt & B Motor & C Stainless Blade & D Rechargeable Battery & E Motor speed Controller \\
\hline Ease of handling & 0 & + & - & 0 & + \\
\hline Ease of use & + & - & + & + & + \\
\hline Durability & - & - & 0 & + & - \\
\hline Ease of manufacture & - & 0 & - & - & 0 \\
\hline Cost & - & - & + & - & 0 \\
\hline Ease of maintenance & 0 & - & + & 0 & + \\
\hline Portability & 0 & 0 & 0 & 0 & 0 \\
\hline Sum +’s & 2 & 1 & 4 & 3 & 3 \\
\hline Sum 0’s & 3 & 3 & 2 & 3 & 4 \\
\hline Sum -'s & 3 & 4 & 2 & 2 & 1 \\
\hline Net score & -1 & -3 & +2 & +1 & +2 \\
\hline Rank & 4 & 5 & 1 & 3 & 1 \\
\hline Continue? & No & No & Yes & Yes & Yes \\
\hline
\end{tabular}

Concept scoring: The relative performance ratings are -

Table 5. Performance ratings.

\begin{tabular}{cc}
\hline Relative Performance & Rating \\
\hline Much worse than reference & 1 \\
Worse than reference & 2 \\
Same as reference & 3 \\
Better than reference & 4 \\
Much better than reference & 5 \\
\hline
\end{tabular}


Table 6. Concept scoring of automatic vegetable chopper.

\begin{tabular}{|c|c|c|c|c|c|c|c|}
\hline \multirow[b]{2}{*}{ Selection criteria } & \multirow[b]{2}{*}{ Weight } & \multicolumn{2}{|c|}{ C Stainless Blade } & \multicolumn{2}{|c|}{ D Rechargeable Battery } & \multicolumn{2}{|c|}{ E Motor speed Controller } \\
\hline & & Rating & weighted score & Rating & Weighted score & Rating & weighted score \\
\hline Ease of handling & $15 \%$ & 3 & 0.45 & 2 & 0.30 & 4 & 0.6 \\
\hline Ease of use & $10 \%$ & 4 & 0.4 & 4 & 0.4 & 2 & 0.2 \\
\hline Portability & $5 \%$ & 2 & 0.1 & 3 & 0.15 & 2 & 0.3 \\
\hline Ease of manufacture & $12 \%$ & 3 & 0.36 & 2 & 0.24 & 3 & 0.36 \\
\hline Cost & $22 \%$ & 2 & 0.44 & 3 & 0.66 & 3 & 0.66 \\
\hline Ease of maintenance & $17 \%$ & 4 & 0.68 & 2 & 0.34 & 2 & 0.34 \\
\hline Durability & $9 \%$ & 5 & 0.45 & 3 & 0.27 & 4 & 0.36 \\
\hline \multirow[t]{3}{*}{ Aesthetics } & $9 \%$ & 4 & 0.36 & 2 & 0.18 & 2 & 0.18 \\
\hline & Total score & \multicolumn{2}{|r|}{3.24} & \multicolumn{2}{|r|}{2.54} & \multicolumn{2}{|r|}{3} \\
\hline & Continue? & \multicolumn{2}{|r|}{ Develop } & \multicolumn{2}{|r|}{ No } & \multicolumn{2}{|r|}{ Develop } \\
\hline
\end{tabular}

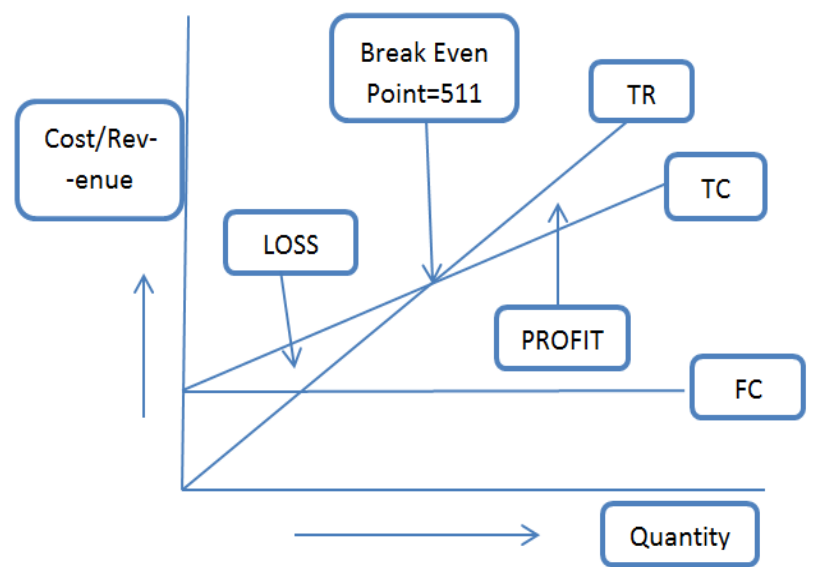

Figure 3. Break even point analysis.

designing and development of an innovative and unique automatic vegetable chopper. Product design also emphasizes on quality and performance of product according to customer specifications. This project focuses on the design and development of automatic vegetable chopper with respect to combine art, science and technology to create usable and desirable products for consumers. In the end, the goal of project design is to build a product that will sell well, thus many of product designs focus on the user and human factors.

\section{REFERENCES}

[1] K. T. Ulrich and S. D. Eppinger, "Product Design and Development,” 2nd Edition, McGraw-Hill, New York, 2000.

[2] J. Nevins and D. Whitney, "Concurrent Design of Products and Processes,” McGraw-Hill, New York, 1989.

[3] H. J. Wassenaar and W. Chen, "An Approach to Decision-Based Design,” Proceedings of ASME DETC'01, Pittsburgh, 9-12 September 2001.

[4] S. Pugh, “Total Design-Integrated Methods for Success- ful Product Engineering,” Addison-Wesley, Boston, 1990.

[5] D. L. Thurston and J. V. Carnahan, "Fuzzy Ratings and Utility Analysis in Preliminary Design Evaluation of Multiple Attributes,” Journal of Mechanical Design, Vol. 114, No. 4, 1992, pp. 648-658. http://dx.doi.org/10.1115/1.2917056

[6] S. H. Yeo, M. W. Mak and A. P. Balon, "Analysis of Decision-Making Methodologies for Desirability Score of Conceptual Design,” Journal of Engineering Design, Vol. 15, No. 2, 2004, pp. 195-208. http://dx.doi.org/10.1080/09544820310001642191

[7] A. M. King and S. Sivaloganathan, "Development of a Methodology for Concept Selection in Flexible Design Strategies," Journal of Engineering Design, Vol. 10, No. 4, 1999, pp. 329-349. http://dx.doi.org/10.1080/095448299261236

[8] T. K. See and K. Lewis, "Multi Attribute Decision Making Using Hypothetical Equivalents," Proceedings of ASME DETC'02, Montreal, 29 September-2 October 2002.

[9] J. Hauser and D. Clausing, “The House of Quality,” Harvard Business Review, May 1988, pp. 67-73.

[10] M. Salonen and M. Perttula, "Utilization of Concept Selection Methods-A Survey of Finnish Industry," Proceeding of IDETC/CIE, Long Beach, 24-28 September 2005, pp. 18-27.

[11] J. Wang, "Improved Engineering Design Concept Selection Using Fuzzy Sets,” International Journal of Computer Integrated Manufacturing, Vol. 15, No. 1, 2002, pp. 18-27. http://dx.doi.org/10.1080/09511920110034996

[12] N. P. Suh, “The Principles of Design,” Oxford University Press, New York, 1990.

[13] M. Hu and J. Pieprzak, "Using Axiomatic Design to Improve Conceptual Design Robustness in Design for Six Sigma (DFSS) Methodology," International Journal of Six Sigma and Competitive Advantage (IJSSCA), Vol. 1, No. 3, 2005, pp. 245-262. http://dx.doi.org/10.1504/IJSSCA.2005.008091 